\title{
(Des)encontros entre Giorgio Agamben e Michel Foucault: o que resta do Estado de direito no Brasil
}

\author{
(Dis)agreements between Giorgio Agamben and Michel \\ Foucault: what remains of the rule of law in Brazil
}

\section{(Des)encuentros entre Giorgio Agamben y Michel Foucault: lo que queda del Estado de derecho en Brasil}

\author{
(iD) Carlos Henrique Aguiar Serra \\ Universidade Federal Fluminense, Niterói, Rio de Janeiro, Brasil \\ chaserra@id.uff.br \\ iD Luís Antônio Francisco de Souza \\ Universidade Estadual Paulista, Marília, São Paulo, Brasil \\ luis.af.souza@unesp.br
iD (9) Raphael Guazzelli Valério Universidade Federal de Pernambuco, Recife, Pernambuco, Brasil raphael.guazzelli@ufpe.br

\begin{abstract}
Resumo: Este artigo explora as convergências e divergências conceituais e teóricas em alguns trabalhos de Michel Foucault e Giorgio Agamben, dando ênfase às noções de estado de exceção e biopolítica. Argumentase que o quadro analítico debatido pelos autores permite compreender por que, na sociedade brasileira atual, a democracia vem se convertendo cada vez mais em um grande mecanismo de gestão biopolítica que tem, em seu centro, a adoção de medidas e dispositivos típicos do estado de exceção, como a autorização da morte de suspeitos e inimigos e a suspensão de direitos e garantias constitucionais. A base empírica para discussão teórica é a recente experiência de intervenção militar na segurança pública no Rio de Janeiro, com suas medidas de exceção, baseadas na ocupação do território, na militarização social, no controle
\end{abstract}


de acesso e na impunidade diante das violações. A intervenção, nesse sentido, é um laboratório do estado de exceção permanente que está se instalando paulatinamente na sociedade brasileira.

Palavras-chave: Michel Foucault. Giorgio Agamben. Estado de Exceção. Biopolítica. Violência.

Abstract: This article explores the conceptual and theoretical convergences and divergences in some works by Michel Foucault and Giorgio Agamben, emphasizing the notions of state of exception and biopolitics. It is argued that the analytical framework discussed by the authors allows us to grasp why, in the current Brazilian society, democracy has increasingly become a mechanism of biopolitical management that has at its core the adoption of typical measures and devices of the state of exception, such as authorized killing of suspects and enemies and suspended constitutional rights and guarantees. The empirical basis for theoretical discussion is the recent experience of military intervention in Rio de Janeiro's public security, with exception measures of its own, based on territory occupation, social militarization, access control, and impunity in the face of violations. Thus, intervention is a laboratory for a permanent state of exception that has been gradually establishing in Brazilian society.

Keywords: Michel Foucault. Giorgio Agamben. State of Exception. Biopolitics. Violence.

Resumen: Este artículo explora las convergencias y divergencias conceptuales y teóricas en algunos trabajos de Michel Foucault y Giorgio Agamben, enfatizando las nociones de estado de excepción y biopolítica. Se argumenta que el marco analítico debatido por los autores nos permite entender por qué, en la sociedad brasileña actual, la democracia se está convirtiendo cada vez más en un gran mecanismo de gestión biopolítica que tiene, en su centro, la adopción de medidas y de dispositivos típicos del estado de excepción, como la autorización del asesinato de sospechosos y enemigos y la suspensión de derechos y garantías constitucionales. La base empírica para discusión teórica es la reciente experiencia de intervención militar en la seguridad pública en Río de Janeiro, con sus medidas de excepción, basadas en la ocupación del territorio, la militarización social, el control de acceso y la impunidad ante las 
violaciones. La intervención, en este sentido, es un laboratorio del estado de excepción permanente que se instala gradualmente en la sociedad brasileña.

Palabras clave: Michel Foucault. Giorgio Agamben. Estado de Excepción. Biopolítica. Violencia.

Data de recebimento: 07/05/2020

Data de aprovação: 16/09/2020
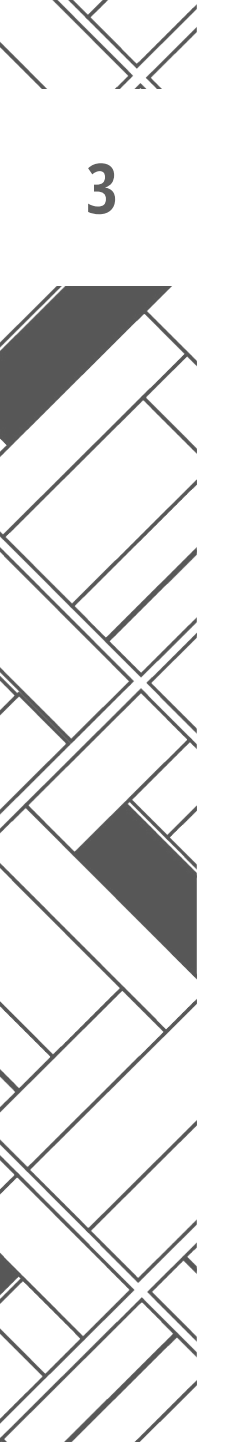


\section{Introdução}

A criação de um novo uso só é possível ao homem se ele desativar o velho uso, tornando-o inoperante (AGAMBEN, 2007, p. 75).

O propósito deste artigo é buscar as convergências e divergências entre alguns textos de Giorgio Agamben e Michel Foucault. Interessa aqui refletir a respeito do pensamento político de Agamben no que concerne mais especificamente às suas formulações teóricas sobre a noção de estado de exceção, em sua conexão com as formulações de Foucault sobre biopolítica. Com esse debate, pretende-se realizar uma genealogia da política contemporânea. Uma aproximação mais visível entre Agamben e Foucault reside na importância dada pelos autores à noção de biopolítica, muito embora seus olhares sejam distintos. O interesse não é apenas teórico, pois entendemos que os autores podem ser utilizados para compreender a complexidade da sociedade brasileira contemporânea. Portanto, o que está no centro da reflexão são as ameaças endereçadas à cidadania e à democracia no Brasil.

Agamben, nascido em 1942, comenta aspectos da obra de Foucault ao publicar "Homo Sacer" em 1995. Uma primeira distinção significativa entre Agamben e Foucault diz respeito aos procedimentos metodológicos. Em Foucault, observa-se sua opção por uma genealogia do poder, que é um procedimento de uma história do presente. Agamben procede a uma hermenêutica política dos conceitos. Sua proposta consiste em uma explicitação da relação entre a potência do vivente e os dispositivos políticos, sendo que a atual fase do capitalismo representa uma acumulação de dispositivos que abrangem todos os aspectos da vida humana (VALERIO, 2019, p. 37-38). O que denominamos sujeito é o resultado de uma tensão entre poder e potência, entre controles e vida política.

A genealogia de Foucault possui como referência fundamental a perspectiva teórico-metodológica de Nietzsche na medida em que se "opõe à pesquisa de origem" (FOUCAULT, 1984, p. 
12). Em meados dos anos 1970, Foucault produziu uma ruptura epistemológica em relação à tradição dos estudos sobre poder, na medida em que desvinculou o poder da análise específica do Estado. Assim, o poder passou a ser tomado como estratégia de dominação, como forma de produção de verdade e como constituição de sujeitos. Interessou a ele estudar a mecânica do poder. A biopolítica, em Foucault, corresponde à modalidade de poder que incide sobre coletividades vivas, dentro do princípio da política que faz viver e deixa morrer. Em Agamben, a política aparece com sendo sempre biopolítica, pois é constituída pelo procedimento do estado de exceção, no qual a vida nua é tematizada pelo político (LEMKE, 2003; AGAMBEN, 2004; FOUCAULT, 1999). Mais à frente, faremos uma distinção entre a biopolítica e o estado de exceção.

Com essas questões em vista, o artigo pretende destacar as divergências e convergências teóricas para refletir sobre a segurança pública na cidade do Rio de Janeiro. A hipótese que configura as principais afirmações aqui presentes aponta para a análise do Estado brasileiro como mecanismo de gestão que demarca os espaços indefinidos entre lei e ordem, regra e exceção, pacificação e guerra. Em poucas palavras, nos interessa demonstrar que as contradições do estado de direito podem ser compreendidas a partir das noções de estado de exceção e biopolítica.

\section{Dispositivo ou paradigma?}

O dispositivo é, antes de tudo, uma máquina que produz subjetivação e somente enquanto tal é também uma máquina de governo (AGAMBEN, 2009, p. 46).

Um dos eixos da comparação metodológica entre os dois autores é o uso do conceito de dispositivo. Foucault concebe o dispositivo como um conjunto de discursos, instituições, arquiteturas, leis e regulamentos. O dispositivo estabelece uma rede entre elementos heterogêneos, além de possuir função estratégica, 
e sua configuração histórica muda. Em outros termos, dispositivo articula estratégias de poder, discursos de verdade, processos de subjetivação. Esse tripé hermenêutico proposto por Foucault está presente em suas análises, mutatis mutandis, desde a "História da Loucura" até a "História da Sexualidade". Nesse sentido, pode-se falar em dispositivo da sexualidade, dispositivo disciplinar e dispositivo biopolítico, considerando o caráter ao mesmo tempo analítico e histórico dos dispositivos. O dispositivo, portanto, abrange processos abstratos e estratégias concretas (REVEL, 2011).

Para Agamben, dispositivo compreende aquilo que tem "capacidade de capturar, orientar, determinar, interceptar, modelar, controlar e assegurar os gestos, as condutas, as opiniões, os discursos dos seres viventes" (AGAMBEN, 2009, p. 40). O dispositivo não se refere apenas às prisões e seus discursos, às fábricas e suas técnicas, às disciplinas e ao direito, mas também aos objetos, por mais simples que possam ser, como caneta, cigarro, computadores etc. A linguagem, nesse sentido, é um dos mais antigos dispositivos (AGAMBEN, 2009, p. 40-41). Sendo assim, Agamben amplia o conceito de Foucault na medida em que dispositivo compreende os aparatos criados pelo homem em razão de sua funcionalidade (VALERIO, 2019, p. 36). Mas é preciso reforçar a ideia segundo a qual o dispositivo é um conceito aglutinador a partir do qual o que se pretende frisar são as diferentes formas de captura de corpos e ações humanas. Dessa forma, o estado de exceção como dispositivo não é apenas uma limitação pertinente ao domínio jurídico-político; mais que isso, ele articula as estratégias concretas que se colocam fora e dentro da lei, de forma simultânea. Sendo assim, estado de exceção é uma estratégia biopolítica de governo, constituindo um dispositivo ou um paradigma complexo.

Diferentemente de Foucault, Agamben propôs um novo sentido para o conceito de paradigma. Os problemas teóricos, políticos, filosóficos, jurídicos não são apenas fenômenos históricos; são, na verdade, paradigmas que expressam a relação fundamental entre vida e poder. Ou seja, são exemplos, singularidades ou modelos que permitem tornar inteligíveis os processos históricos concretos. 
As regras científicas gerais são substituídas pelo paradigma, assim como a lógica universal da lei é tomada como exemplo ou como um caso singular (AGAMBEN, 2009, pp. 13-16). Exemplificando, a lei pressupõe o não jurídico, assim como o direito pressupõe a exceção; a política pressupõe o campo de concentração, a educação pressupõe a disciplina etc. Há uma relação potencial entre o geral e o particular, entre normal e patológico, entre norma e exceção, entre discurso e poder. "A linguagem é o soberano que, em permanente estado de exceção, declara que não existe um fora da língua, que ela está sempre além de si mesma" (AGAMBEN, 2004, p. 29).

Diversos conceitos de Agamben aparecem sob uma dupla rubrica: o paradigma e/ou dispositivo da soberania. Lendo Agamben com atenção, a distinção entre estes termos não é absoluta; ocorre o mesmo com a noção de vida nua, que ora é empregada como sinônimo de vida biológica, ora como artifício político produzido pelo poder soberano. Agamben dedicou dois pequenos textos aos conceitos de dispositivo e paradigma. Poderíamos dizer que o primeiro tem o caráter de construto teórico, o segundo tem um caráter metodológico. O primeiro é usado para descrever coisas/experiências/ relações: uma lei, uma norma, um objeto, uma linguagem. Assim, podemos dizer que o dispositivo da soberania produz a vida nua.

Já o conceito de paradigma é usado por Agamben para explicar e justificar suas opções metodológicas. Dentre as diversas críticas lançadas ao seu pensamento, uma, de especial importância, diz respeito ao emprego, por parte do filósofo italiano, de figuras como o homo sacer, o campo de concentração, o muçulmano, entre outras. Ora, estas figuras são históricas, quer dizer, podemos encontrar sua materialidade em fatos ocorridos no passado. De modo que Agamben estaria assim nos oferecendo meras teses historiográficas e que, ao fazê-lo, corre o risco de cometer o pecado mais mortal dos historiadores, o anacronismo. Com o termo paradigma, Agamben procura desfazer a confusão. O paradigma seria, de fato, uma positividade histórica, mas que teria, pela força do exemplo, a capacidade de estender uma grade de inteligibilidade a outros fenômenos históricos. 
(Des)encontros entre Giorgio Agamben e Michel Foucault: o que resta do Estado de direito no Brasil Carlos Henrique Aguiar Serra • Luís Antônio Francisco de Souza • Raphael Guazzelli Valério

Portanto, o conceito de paradigma, ou de exemplo, permite evitar os pares antinômicos. O termo grego para-deígma refere-se àquilo que se coloca ao lado. Sendo assim, para o autor, paradigma significa: a) os casos do mesmo gênero; b) uma singularidade entre outras, valendo também por todas elas; e c) um caso particular, além de um exemplo. "Nem particular nem universal, o exemplo é um objeto singular que, digamos assim, se dá a ver como tal, mostra a sua singularidade" (AGAMBEN, 1993, p. 16; VALERIO, 2019, p. 61). Ou seja, no conceito de paradigma, a exceção se torna permanente e, portanto, ocupa o lugar da regra, do direito. O poder soberano e o direito dependem da exceção. Assim, a zoé substitui a bíos e constitui um paradigma da exceção soberana, sendo seu exemplo paradigmático'. Dessa forma, paradigma é ao mesmo tempo exemplar e singular. O paradigma é histórico, mas não originário. A historicidade do paradigma "não está nem na diacronia nem na sincronia, mas no entrecruzamento delas" (AGAMBEN, 2009, p. 156-157).

\section{Estado de exceção e vida nua}

Se algo caracteriza, portanto, a democracia moderna em relação à clássica, é que ela se apresenta desde o início como uma reivindicação e uma liberação da zoé, que ela procura constantemente transformar a mesma vida nua em forma de vida e de encontrar, por assim dizer, o bíos da zóe (AGAMBEN, 2002, p. 17).

Agamben realiza um diálogo com Walter Benjamin e Carl Schmitt sobre a noção de estado de exceção². Mas, em "Homo Sacer", Agamben reconhece a importância da discussão de

\footnotetext{
1 O par categorial bíos/zoé possui elevada importância no interior do projeto Homo Sacer, e as primeiras linhas do projeto são dedicadas a estes conceitos. Agamben argumenta que os gregos antigos possuíam duas palavras para designar aquilo que as línguas modernas chamam de vida. Uma, zoé, diz respeito ao simples fato da vida, vida esta que os homens dividiam com os animais e os deuses. Outra, bíos, refere-se a um gênero próprio de vida acessível apenas aos homens, quer dizer, uma vida qualificada, ética e política.

2 “A tradição dos oprimidos nos ensina que o 'estado de exceção' em que vivemos é na verdade a regra geral. Precisamos construir um conceito de história que corresponda a essa verdade. Nesse momento, percebemos que nossa tarefa é originar um verdadeiro estado de exceção; com isso, nossa posição ficará mais forte na luta contra o fascismo" (BENJAMIN, 1985, p. 226). Valeria a pena recuperar este diálogo entre Benjamin (1985) e Schmitt (2006). Para este último, a soberania se funda sobre o paradigma da excepcionalidade, nesse sentido, sua obra é uma justificação do estado de exceção como ditadura; para o primeiro, uma concepção revolucionária de exceção é possível (LEUTÉRIO, 2014; GUSI, 2015).
} 
Foucault sobre biopolítica. Agamben, ao mesmo tempo em que reconhece, faz reparos e se apropria das formulações de autores anteriores. Ele afirma que talvez Foucault "jamais tenha deslocado a sua investigação para as áreas por excelência da biopolítica moderna: o campo de concentração e a estrutura dos grandes estados totalitários dos Novecentos", afinal, "o ingresso da zóe na esfera da polis, a politização da vida nua como tal, constitui o evento decisivo da modernidade, que assinala uma transformação radical das categorias político-filosóficas do pensamento clássico" (AGAMBEN, 2002, p. 12).

Para Agamben, o diálogo mais profícuo seria entre Foucault e Arendt, já que as “duas análises não podem ser separadas e que a implicação da vida nua na esfera política constitui o núcleo originário - ainda que encoberto - do poder soberano" (AGAMBEN, 2002, p. 14). Nesses termos, a biopolítica é uma invenção antiga, já que ao colocar "a vida biológica no centro de seus cálculos, o Estado moderno não faz mais, portanto, do que reconduzir à luz o vínculo secreto que une o poder à vida nua" (AGAMBEN, 2002, p. 14).

Agamben ainda é mais contundente no postulado de que a "dupla categorial fundamental da política ocidental não é aquela amigo-inimigo, mas vida nua-existência política, zoé-bíos, exclusão-inclusão" (AGAMBEN, 2002, p. 16). Dessa forma, segundo o autor, a política somente existe na medida em que o "homem é o vivente que, na linguagem, separa e opõe a si a própria vida nua e, ao mesmo tempo, se mantém em relação com ela numa exclusão inclusiva" (AGAMBEN, 2002, p. 16). A divergência de Agamben em relação a Foucault fica assim evidenciada no paradoxo de uma "vida matável e insacrificável do homo sacer". Sendo assim,

Lado a lado com o processo pelo qual a exceção se torna em todos os lugares a regra, o espaço da vida nua, situado originariamente à margem do ordenamento, vem progressivamente a coincidir com o espaço político, e exclusão e inclusão, externo e interno, bíos e zoé, direito e fato entram em uma zona de irredutível indistinção (AGAMBEN, 2002, p.16). 
Então, há uma imbricação necessária, no âmbito do Estado contemporâneo, entre biopolítica, poder soberano e estado de exceção. Na verdade, o que se quer salientar é que essa articulação pode ser bem compreendida no exercício político do estado de exceção, que se utiliza de forma potente da biopolítica e do poder soberano. Nesse sentido, o estado de exceção tem como outra peculiaridade a íntima interface entre poder soberano e biopolítica.

Para Agamben, o "estado de exceção apresenta-se como forma legal daquilo que não pode ter forma legal", e mais, apresenta-se como um "patamar de indeterminação entre democracia e absolutismo" (AGAMBEN, 2004, p. 12). "[E]star-fora e, ao mesmo tempo, pertencer: tal é a estrutura topológica do estado de exceção, e apenas porque o soberano que decide sobre a exceção é, na realidade, logicamente definido por ela em seu ser, é que ele pode também ser definido pelo oxímoro êxtase-pertencimento" (AGAMBEN, 2004, p. 57). Há uma imbricação de diversos elementos, sendo possível refletir a respeito da interpretação de conexões entre o estado de exceção, o absolutismo, a lógica do inimigo e a cultura punitivista. Um aspecto muito relevante na definição do estado de exceção é que ele é um vazio de Direito, um "espaço anômico onde o que está em jogo é uma força-de-lei sem lei" (AGAMBEN, 2004, p. 61).

Sendo assim, as incongruências a parentes do estado de direito no Brasil - consagração de direitos civis e políticos e militarização crescente - ficam esclarecidas.

O espaço político da soberania ter-se-ia constituído, portanto, através de uma dupla exceção, como uma excrescência do profano no religioso e do religioso no profano, que configura uma zona de indiferença entre sacrifício e homicídio. Soberana é a esfera na qual se pode matar sem cometer homicídio e sem celebrar um sacrifício, e sacra, isto é, matável e insacrificável, é a vida que foi capturada nesta esfera (AGAMBEN, 2002. p. 91).

O conceito de estado de exceção pode aparecer sob três aspectos: a) como uma categoria analítica para caracterizar uma si- 
tuação singular de indeterminação; b) como exceção permanente; e c) como a supressão da política (SANTOS, 2007). Trata-se, então, de uma exceção permanente, mesmo sem a supressão das leis. Isto porque a lei, para ser aplicada, é, ao mesmo tempo, desaplicada; o estado de exceção, assim, ativa e desativa o dispositivo guerreiro (AGAMBEN, 2004, p. 27-28).

O poder político está fundado na separação do fato simples de viver, a vida nua, das formas qualificadas da vida. A conexão entre vida política e vida nua está presente na definição aristotélica do homem como animal possuidor de linguagem (zoon logon ekhon). Segundo Aristóteles, a política nasce com a linguagem. A voz, que é comum a todos os animais, pode ser capaz de expressar prazer e desprazer; mas somente a linguagem é um atributo essencialmente humano e, por essa razão, pode expressar a distinção entre justo e injusto, fundando a comunidade. A relação entre vida e política é que está em jogo no momento da passagem da voz (phoné) à linguagem (lógos) (VALERIO, 2019, p. 42-44). Portanto, uma das características intrínsecas à constituição da modernidade reside na ampliação do fosso que separa zoé de bíos, direito de fato, inclusão de exclusão (VALERIO, 2019, p. 45)³.

\section{Bio, tanatos e necropolítica}

Aquém, portanto, do grande poder absoluto, dramático, sombrio que era o poder da soberania, e que consistia em poder fazer morrer, eis que aparece agora, com essa tecnologia do biopoder, com essa tecnologia do poder sobre a "população" enquanto tal, sobre o homem enquanto ser vivo, um poder contínuo, científico, que é o poder de "fazer viver". A soberania fazia morrer e deixava viver. E eis que agora aparece um poder que eu chamaria de regulamentação e que consiste, ao contrário, em fazer viver e em deixar morrer (FOUCAULT, 1999. p. 294).

3 Esta zona de indistinção que permite o surgimento do espaço vazio, o de fora incluído na norma, permite que Bruno Latour (1994) fale dos híbridos: cisão entre o natural e o social, através de um jogo tanto de tradução como de purificação. 
Foucault é um dos principais teóricos contemporâneos a respeito das instituições disciplinares existentes no capitalismo. De sua obra, nos interessa recuperar em específico as formulações sobre o conceito de biopolítica e sobre os mecanismos da punição disciplinar. A hipótese central que Foucault elabora é que, para além da dominação repressiva sobre uma classe trabalhadora, é necessário compreender o "como" do poder em termos de seu exercício e seus efeitos de disciplinamento geral da sociedade (FOUCAULT, 1979).

A disciplina implica no exercício do poder de punir cujo objetivo é a gestão de punir com eficiência e com minimização da dor física, reduzindo a possibilidade de resistência. Assim, o poder não é visto em seu aspecto jurídico, segundo o modelo da soberania, mas em seu efeito estratégico, segundo o modelo da guerra (FOUCAULT, 1984). Para Foucault, a disciplina é mais uma forma de constituição de sujeitos do que uma forma de dominação política. As disciplinas nascem como técnica que incide sobre o corpo, para produzir corpos viáveis para a nascente sociedade disciplinar (FOUCAULT, 1984). A arte de punir é uma estratégia política que aumenta a submissão e diminui a revolta. Mais do que isso, a punição é para além de uma inflição de dor sem sentido, pois o que se almeja é um excesso punitivo, de forma sacralizada, infame e racional. (ZAFFARONI, 1991). Assim sendo, é possível sustentar também que a disciplina exerce um papel político na prisão e se articula com esta "arte de punir", na medida em que não se deve desconsiderar a perspectiva do panóptico.

A biopolítica configura-se em uma forma de poder que, diferentemente da disciplina, passa a se exercer sobre coletividades, sobre multiplicidades. Foucault (1985), no capítulo Direito de morte e poder sobre a vida, aponta para o papel da biopolítica como mecanismo de gestão da vida, tratando-se de um poder que investe sobre o ser humano como ser vivo, como população, de onde se pode extrair um determinado quantum de ação ótima, tendendo para uma normalização do corpo social. 
Ora, agora que o poder é cada vez menos o direito de fazer morrer e cada vez mais o direito de intervir para fazer viver, e na maneira de viver, e no 'como' da vida, a partir do momento em que, portanto, o poder intervém sobretudo nesse nível para aumentar a vida, para controlar seus acidentes, suas eventualidades, suas deficiências, daí por diante a morte, como termo da vida, é evidentemente o termo, o limite, a extremidade do poder. Ela está do lado de fora, em relação ao poder: é o que cai fora de seu domínio, e sobre o que o poder só terá domínio de modo geral, global, estatístico. Isso sobre o que o poder tem domínio não é a morte, é a mortalidade. E, nessa medida, é normal que a morte, agora, passe para o âmbito privado e do que há de mais privado. Enquanto, no direito de soberania, a morte era o ponto em que mais brilhava, da forma mais manifesta, o absoluto do poder do soberano, agora a morte vai ser, ao contrário, o momento em que o indivíduo escapa a qualquer poder, volta a si mesmo e ensimesma, de certo modo, em sua parte mais privada. O poder não conhece a morte. No sentido estrito, o poder deixa a morte de lado (FOUCAULT, 1999, p. 295-296).

A partir da segunda metade do século XVIII, política médica, higiene pública e medicina social já podiam ser inscritas nos quadros de uma biopolítica. O que caracteriza esse poder geral é a população como um conjunto de seres vivos, com especificidades geográficas, históricas e políticas. A população demanda técnicas e saberes diversos do poder disciplinar. No século XVIII, novos problemas, novas técnicas e novos objetos políticos e econômicos demandam um conjunto novo de dispositivos que controlam a vida.

Agamben (2002) retoma a hipótese da biopolítica de Foucault. A principal diz respeito à temporalidade do biopoder. Para Foucault, a política se transforma em biopolítica a partir do século XVIII; para Agamben, a política nasce como biopolítica. Foucault analisa os dispositivos concretos de poder que constituem a vida e os corpos. Agamben analisa o discurso jurídico-político clássico do poder, em especial, a soberania, supostamente negligenciado por Foucault. Mas as principais mudanças na noção de biopolítica em Agamben 
dizem respeito ao sentido da vida, ou melhor, ao processo de submissão da vida nua ao quadro mais amplo dos dispositivos do poder soberano, tendo como foco o paradigma do campo de concentração. Trata-se, portanto, de uma expansão da biopolítica para as estratégias de matabilidade das vidas que não merecem ser vividas e da disponibilidade dos corpos aos ensaios do poder, quer pela psiquiatria, medicina ou economia. O que está em jogo, portanto, é o valor próprio da vida e as qualidades específicas atribuídas ao ser humano, incluindo a definição mesma do humano na modernidade, de seu caráter sagrado, mas insacrificável.

O sentido do sagrado deve ser esclarecido e questionado, segundo a metodologia da superação das aporias proposta por Agamben. Sacer é uma palavra ambígua. Significa ao mesmo tempo abjeto, ignominioso e augusto, específico dos deuses. E sacros são tanto a lei como aquele que a protege e a viola. "Aquele que violou a lei, em particular o homicida, é excluído da comunidade, é, pois, repelido, abandonado a si mesmo e, como tal, pode ser morto sem delito" (AGAMBEN, 2006, p. 142). No direito romano antigo, aparece essa ambiguidade na forma da sacratio que decreta a impunidade da morte e a impossibilidade do sacrifício; a consagração faz a vítima do sacrifício passar do direito humano ao direito divino, do profano ao sacro. No caráter indiscernível do sagrado é que reside a especificidade do homo sacer, pois ele é excluído do direito humano, sua morte não é punível, e, ao mesmo tempo, não pode ser consagrado. Sagrado e matável, esta é a aporia. No estado de exceção, a vida, protegida pelos estatutos jurídicos democráticos e considerada como sagrada, representa também esta duplicidade, pois é ao mesmo tempo divina, portanto, insacrificável e humana, por conseguinte, matável. "A vida insacrificável e, todavia, matável, é a vida sacra" (AGAMBEN, 2006, p. 90).

A vida capturada pela soberania, o bando soberano, não tem substrato nem essência, é uma pura relação de duplo vínculo: exclusão inclusiva ou inclusão exclusiva. "Soberana é a esfera na qual se pode matar sem cometer homicídio e sem celebrar um sacrifício, e sacra, isto é, matável e insacrificável, é a vida que foi capturada nesta esfera" (AGAMBEN, 2006, p. 91). A reivindicação 
do caráter sagrado da vida é sua exposição ao poder de morte (VALERIO, 2018, p. 78-79). Portanto, “Nem bíos político, nem zoé natural, a vida sacra é a zona de indistinção na qual implicando-se e excluindo-se um ao outro, estes se constituem mutuamente" (AGAMBEN, 2006, p. 98). No mundo contemporâneo, a politização da vida, sua captura tanto pelo dispositivo biopolítico como pela disciplina, produz esta cesura entre a vida e a vida nua, que é indigna de ser vivida, sendo que esta última penetra profundamente nas vidas dos seres humanos que, agora, são definidos pelo seu grau de descartabilidade. A implicação da vida nua na vida política torna os seres humanos potencialmente excedentes. Ou seja, neste momento, o estado de exceção produz não mais o bíos, mas o tanatos, assim, a biopolítica converte-se em tanatospolítica.

Ao colocarmos, no entanto, a experiência do poder de morte do imperialismo, a biopolítica e a tanatospolítica sofrem uma radicalização, porque o poder soberano é exercido sem peias com o fim de acumulação primitiva de capital. A Europa e os Estados Unidos enriqueceram e produziram seus referenciais de democracia e de direito a partir da violência brutal produzida por exploração, espoliação, comercialização, êxodo, segregação e violência letal contra os povos colonizados. Como analisaremos mais à frente, tais práticas estão devidamente inseridas no Brasil. Apesar de este artigo não ter o propósito de promover uma discussão detida sobre este processo, é possível fazer uma aproximação com a noção de necropolítica.

Tentei demonstrar que a noção de biopoder é insuficiente para dar conta das formas contemporâneas de submissão da vida ao poder de morte. Além disso, propus a noção de necropolítica e de necropoder para dar conta das várias maneiras pelas quais, em nosso mundo contemporâneo, as armas de fogo são dispostas com o objetivo de provocar a destruição máxima de pessoas e criar 'mundos de morte', formas únicas e novas de existência social, nas quais vastas populações são submetidas a condições de vida que Ihes conferem o estatuto de 'mortosvivos' (MBEMBE, 2017, p.71). 
Ainda que este seja o pano de fundo das suas análises sobre necropoder, Achille Mbembe apresenta um quadro histórico mais complexo na medida em que não reforça uma perspectiva eurocêntrica, ao contrário, quer ver a Europa a partir da colônia, e, assim, o imperialismo ganha centralidade na narrativa sobre a violência (e não apenas a razão política e a democracia, filhas da violência colonial). Embora o autor pense na situação da Faixa de Gaza, suas conclusões podem ser expandidas.

Se observarmos a partir da perspectiva da escravidão ou da ocupação colonial, morte e liberdade estão irrevogavelmente entrelaçadas. Como já vimos, o terror é uma característica que define tanto os Estados escravistas quanto os regimes coloniais contemporâneos. Ambos os regimes são também instâncias e experiências específicas de ausência de liberdade. Viver sob a ocupação contemporânea é experimentar uma condição permanente de 'viver na dor': estruturas fortificadas, postos militares e bloqueios de estradas em todo lugar; construções que trazem à tona memórias dolorosas de humilhação, interrogatórios e espancamentos; toques de recolher que aprisionam centenas de milhares de pessoas em suas casas apertadas todas as noites do anoitecer ao amanhecer; soldados patrulhando as ruas escuras, assustados pelas próprias sombras; crianças cegadas por balas de borracha; pais humilhados e espancados na frente de suas famílias; soldados urinando nas cercas, atirando nos tanques de água dos telhados só por diversão, repetindo slogans ofensivos, batendo nas portas frágeis de lata para assustar as crianças, confiscando papéis ou despejando lixo no meio de um bairro residencial; guardas de fronteira chutando uma banca de legumes ou fechando fronteiras sem motivo algum; ossos quebrados; tiroteios e fatalidades - um certo tipo de loucura (MBEMBE, 2017, pp. 68-69).

Na reflexão de Agamben, a concepção de espécie humana como partícipe de corpo político não impede a ativação da zoé no cerne da bíos. "Ou seja, o povo já traz sempre em si a fratura 
biopolítica fundamental. Ele é aquilo que não pode ser incluído no todo do qual faz parte e não pode pertencer ao conjunto no qual já está desde sempre incluído" (AGAMBEN, 2015, p. 37. grifos no original). Ora, na necropolítica, os povos colonizados, incluídos pela sua exclusão, como sub-raças, como não iguais, como inimigos, como não pertencendo à humanidade, como criminosos, como terroristas, como outsiders, nem chegaram a ser constituídos como povo e, portanto, não são titulares de direitos, não pertencendo à espécie humana. Nesse sentido, somente foram incluídos por um poder que se exerceu como violência, morte e massacre. Os cadáveres da violência colonial são a versão última da vida nua.

\section{O que resta do estado de direito ${ }^{4}$}

Vida supérflua, portanto, cujo preço é tão baixo que não equivale a nada, nem sequer como mercadoria e, ainda menos, humana - é uma espécie de vida cujo valor está fora da economia, correspondendo apenas ao tipo de morte que se Ihe inflige (MBEMBE, 2017, p. 65).

A militarização da segurança pública no Rio de Janeiro pode ser compreendida como um paradigma do estado de exceção. Ela compreende um conjunto amplo de estratégias, táticas, técnicas e ações que visam inserir a guerra na vida, como forma de governo da população negra e periférica. A militarização iniciou-se historicamente com o dispositivo do warfare às drogas nos anos 1970. Ela se intensificou com a guerra ao terror e a expansão dos gastos militares e da indústria de equipamentos armados, usados extensivamente nas guerras externas e internas. Aos poucos, a militarização subverteu o funcionamento "normal" do sistema judicial e político, introduzindo a cisão fundamental entre amigo e inimigo, entre normal e patológico, entre riscos e perigos etc. As estratégias de guerra híbrida, com uso extensivo de forças militares e paramilitares, encontram seu paralelo no chamado lawfare,

40 título do capítulo é inspirado em Agamben (2008) na medida em que parece que os limites do razoável foram ultrapassados e que resta o testemunho da violência, sabendo que as vítimas da violência não podem voltar para contar sua experiência. 
(Des)encontros entre Giorgio Agamben e Michel Foucault: o que resta do Estado de direito no Brasil Carlos Henrique Aguiar Serra • Luís Antônio Francisco de Souza • Raphael Guazzelli Valério

ou seja, o uso militar e político do direito, sobretudo do direito penal (JAKOBS, 2010; FIRMINO, 2018; MARTINS et al., 2019).

O Rio de Janeiro tem estado sob o regime de um estado de exceção permanente, reforçado pela adoção de medidas militarizadas que normalizaram a violência contra populações historicamente excluídas e marginalizadas pelo aparato estatal (PAOLIELLO, 2017)5. É uma grande lista de violência e mortes provocadas pelo estado de exceção. Trata-se, sem dúvida, de um governo de populações periféricas não mais caracterizado apenas pela repressão e pelo terror, mas também e, sobretudo, pelas estratégias de morte. Nesse sentido, e como o presente artigo vem afirmando, o estado de exceção articula-se com a necropolítica (MBEMBE, 2018; GUSSO, SERRA; SOUZA, 2020). A prisão, tortura e assassinato de Amarildo Dias de Souza, em julho de 2013, e o assassinato de Marielle Franco e Anderson Gomes, em março de 2018, são exemplos de estado de exceção incrustado nas políticas militares de segurança. Esses crimes permanecem impunes. Não obstante a repercussão nacional e internacional desses casos, a militarização da segurança e a adoção de agendas punitivistas apenas se acirraram nos últimos anos.

O estado de exceção é uma estratégia jurídica e política, pois permite ampliar a indistinção entre inimigo interno e externo. Bairros, comunidades e cidades sitiadas têm sido submetidos a estratégias que desafiam os limites do direito constitucional. As chamadas forças da ordem adotaram critérios estratégicos, controlando a circulação de pessoas e estabelecendo medidas de fiscalização que virtualmente suspendem a lei dentro do território. As mortes e a violência provocadas pela ação militar tornaram-se norma.

Em 2018, ocorreu a maior ação de intervenção militar ostensiva da história do Rio de Janeiro. A intervenção não apenas serviu de laboratório para medidas repressivas e violentas de segurança

\footnotetext{
5 A militarização tem-se tornado um processo amplamente disseminado no contexto da cidade globalizada e neoliberal, constituindo na verdade um dos aspectos principais da experiência social contemporânea no que se refere à segurança pública e ao controle social do crime e da violência. Não apenas as instituições policiais, as prisões e centros de detenção, mas o planejamento e gestão das cidades têm assumido cada vez mais o aspecto de enclausuramento, fortificação e militarização (Graham, 2016).
} 
como foi um teste de legitimação da gestão militarizada da segurança pública, com seu componente de construção permanente de um inimigo a ser abatido, dentro da lógica da guerra e do confronto armado. A intervenção foi justificada como uma estratégia de guerra contra o crime organizado e contra o tráfico de drogas. Somente na última década, o governo do Rio de Janeiro recorreu às intervenções das Forças Armadas em pelo menos 12 vezes (BIANCHI, 2017). A capital foi ocupada por soldados em uniformes camuflados, atiradores de elite, veículos blindados, bem como foram adotadas diversas estratégias associadas a palcos de guerra. Dessa forma, as Forças Armadas passaram a desempenhar atividades policiais, e as instituições de segurança pública foram adotando estratégias de intervenção, ocupação, circulação e controle de acesso aos territórios típicas dos militares. São tendências simultâneas e complementares: a militarização da segurança e a policialização dos militares.

Essas duas tendências vêm sendo reforçadas pela ocupação de espaços na política e na burocracia estatal por militares da reserva e da ativa, observadas também em vários países. As forças de reserva, como é o caso da Força Nacional de Segurança, estão sendo cada vez mais ativadas para ações de policiamento cotidiano. As intervenções tornaram-se mais comuns em razão das ações de GLO (Garantias de Lei e Ordem), que preveem o emprego das Forças Armadas sempre que se considerar que as instituições da segurança têm sido incapazes para controlar o crime violento, mas o alvo preferencial dessas medidas são as comunidades e os moradores de morros e favelas. As GLO, no sentido aqui empregado, podem ser caracterizadas como medidas jurídicas de exceção.

As estratégias de exceção ficam evidenciadas nas diversas incursões das forças policiais militarizadas nas favelas, impondo toques de recolher bem como provocando prisões ilegais e aumento 
(Des)encontros entre Giorgio Agamben e Michel Foucault: o que resta do Estado de direito no Brasil Carlos Henrique Aguiar Serra • Luís Antônio Francisco de Souza • Raphael Guazzelli Valério

da letalidade de moradores, sobretudo jovens negros ${ }^{6}$. Conforme dados do Observatório da Intervenção, entre fevereiro e dezembro de 2018, as ações militares aumentaram os indicadores de violência como chacinas e "tiroteios". Não obstante, o poder das milícias durante a intervenção não foi afetado7. As operações do Exército, ao contrário, ignoraram conspicuamente as áreas dominadas por paramilitares. Sendo assim, a intervenção não produziu efeito sobre as milícias, o que coloca em xeque todo o argumento favorável à intervenção e à militarização da segurança e da administração pública.

Desde 1995, os governos estaduais do Rio de Janeiro têm optado pela estratégia do confronto, com base na lógica do inimigo, na criminalização da pobreza e na guerra às drogas (BATISTA, 2002). A política das Unidades de Polícia Pacificadora (UPP) não rompeu com esse paradigma. Ao contrário, adotou o modelo de "intervenções táticas", "estabilização" e "implantação", visando ocupação territorial e liquidação dos pontos de armas e drogas (RODRIGUES E SIQUEIRA, 2012; BATISTA, 2012). Nesse sentido, as UPPs inseriram de forma mais incisiva o modelo da violência militar sobre as comunidades submetidas a um estado de exceção. A estratégia da pacificação, assim, foi o prenúncio da tendência de militarização e permitiu a conversão da cidade do Rio de Janeiro numa praça de guerra (MACHADO DA SILVA, 2013; SILVA, 2018). Portanto, a intervenção tornou-se face mais evidente da militarização da segurança pública. Ela colocou moradores dos morros e das favelas em estado de sítio, realizou prisões arbitrárias e matou pessoas consideradas suspeitas. A intervenção militar na segurança pública do Rio de Janeiro, por meio de ajustes legislativos infraconstitucionais e ações tipicamente militares, é parte fundamental da normalização do estado de exceção. E, de uma forma mais ampla, a militarização

6 A intervenção federal na segurança pública do Rio de Janeiro foi uma operação financeiramente custosa e politicamente
perigosa. Em termos de custo, a intervenção empregou 170.000 soldados armados, foram realizadas 360 operaçães, foram
usados equipamentos militares de todos os tipos, sobretudo armas e veículos pesados. Em termos políticos, os militares as-
sumiram a coordenação da segurança, interferiram em decisões que eram de responsabilidade das autoridades civis, assim
como ocuparam o estado do Rio de Janeiro no período eleitoral, num momento em que foram impostos toques de recolher e
limitação de acesso e circulação de moradores, sobretudo nas periferias e morros. O orçamento da intervenção foi da ordem
de $\mathrm{R} \$ 1,2$ bilhão. Para mais detalhes, ver o relatório da intervenção federal: http://observatoriodaintervencao.com.br/ Acesso
em $30 / 01 / 2019$.
7 Em 2018 , pesquisadores e jornalistas estimavam que as milícias se faziam presentes em 37 bairros e 165 favelas da região
metropolitana do RJ, confrontando diretamente o controle territorial do tráfico de drogas, do contrabando de armas e exercen-
do localmente o monopólio da violência, assim como provendo o acesso a vários serviços "públicos" (SPAGNUOLO ET AL, 2018). 
constitui um dispositivo de gestão que amplia a indefinição entre lei e ordem, regra e exceção, pacificação e guerra.

\section{Considerações finais}

Examino essas trajetórias pelas quais o estado de exceção e a relação de inimizade tornaram-se a base normativa do direito de matar. Em tais instâncias, o poder continuamente se refere e apela à exceção, à emergência e a uma noção ficcional do inimigo (MBEMBE, 2018, p. 17).

Observando o quadro teórico e os problemas do estado de direito no Brasil, devemos dar razão ao que Watkin (2013) chama de filosofia da indiferença ao referir-se ao pensamento de Agambem. Sendo assim, há uma indiferença entre democracia e tirania, entre estado de direito e estado de exceção, entre lei e ilegalidade. A proposta deste artigo foi uma tentativa de superar a perspectiva dogmática (SERRA, 2008), ressaltando a indiferença entre estado de exceção, estado punitivo e estado de direito. Se o Estado é também o espaço por excelência da política, esta se despolitiza, quase se esmaece, se esvai e se subtrai pela judicialização sob o peso do estado de exceção. Há, portanto, uma despolitização dos conflitos sociais, mas uma politização da judicialização, que potencializa e tenta legitimar as exceções permanentes. O diálogo entre Agamben e Foucault oferece contribuição para uma tentativa de compreensão da morbidez necropolítica brasileira.

A ressalva necessária a ser feita e reiterada direciona-se aos limites necessários das formulações teóricas de Agamben e Foucault no que diz respeito, especificamente, às concepções de estado de exceção e biopolítica. Assim sendo, as formulações teóricas não devem ser generalizadas, elas são horizontes de possibilidade. As análises de Walter Benjamin são singulares. É nesse sentido que analisamos as contribuições de Agamben e Foucault. Singulares, no sentido de que há todo um campo de ação política que visa 
uma mudança radical: "A tradição dos oprimidos nos ensina que o 'estado de exceção' em que vivemos é na verdade a regra geral. Precisamos construir um conceito de história que corresponda a essa verdade" (BENJAMIN, 1985, 226). Ou seja, nosso presente e nossa singularidade se definem pela luta antifascista.

As condições singulares, mórbidas e necropolíticas estão dadas e, portanto, devem ser desativadas com uma retomada da ação política. Robert Antelme (2013), conhecido memorialista que sobreviveu a um campo de concentração nazista, diz que a condição humana é da ordem da indestrutibilidade. Por mais que os homens morram e sejam mortos por incontáveis estratégias da biopolítica (Foucault), tanatospolítica (Agamben) ou necropolítica (Mbembe), sempre resta algo dessa destruição, sempre há algo além dessa destruição. Por essa razão, os historiadores têm resistido a analisar o chamado holocausto a partir da figura do sacrifício, pois isso poderia significar que os crematórios representavam piras sacrificiais e que, portanto, produziram a sacralização do genocídio. Para além de uma morte de consagração, a violência do estado de exceção requer respostas que apontam para a resistência, para a indestrutibilidade da vida humana. E essas são as contra estratégias políticas que podem ser capazes de desativar os dispositivos de exceção.

\section{Referências}

AGAMBEN, Giorgio. Estado de exceção. São Paulo: Boitempo, 2004.

AGAMBEN, Giorgio. Homo Sacer: o poder soberano e a vida nua. Belo Horizonte: UFMG, 2002.

AGAMBEN, Giorgio. A comunidade que vem. Lisboa: Presença, 1993.

AGAMBEN, Giorgio. Profanações. São Paulo: Boitempo Editorial, 2007. 
AGAMBEN, Giorgio. O que é o contemporâneo? E outros ensaios. Chapecó, SC: Argos, 2009.

AGAMBEN, Giorgio. El tiempo que resta. Madrid: Editorial Trotta, 2006.

AGAMBEN, Giorgio. O que resta de Auschwitz. São Paulo: Boitempo Editorial, 2008.

AGAMBEN, Giorgio. Meios sem fim: notas sobre a política. Belo Horizonte: Autêntica, 2015.

ALVES, José Cláudio Souza. Dos Barões ao extermínio: a história da violência na Baixada Fluminense. Rio de Janeiro: Ed. Sepe / APPH-Clio, 2011.

ANTELME, Robert. A espécie humana. Rio de Janeiro e São Paulo: Record, 2013.

BATISTA, Nilo. Mídia e sistema penal no capitalismo tardio.

Revista Discursos Sediciosos, Rio de Janeiro, v. 12, 2002.

BATISTA, Nilo e BATISTA, Vera Malaguti (orgs.). Paz armada. Rio de Janeiro: Revan, 2012.

BENJAMIN, Walter. Obras escolhidas. Magia e técnica, arte e política. São Paulo: Brasiliense, 1985.

BIANCHI, Paula. Rio chama Exército contra violência pela $12^{\mathrm{a}}$ vez em 10 anos. Adianta? UOL NOTÍCIAS. 29/07/2017. https://noticias.uol.com.br/cotidiano/ultimas-noticias/2017/07/29/rio-chama-exercito-contra-violencia-pela-12-em-10-anos-virou-rotina. htm?cmpid=copiaecola. Acesso 04/08/2020.

FIRMINO, Rodrigo José. Securitização, vigilância e territorialização dos espaços públicos. In BRUNO, Fernanda et al (org). Tecnopolíticas da vigilância. Perspectivas das Margens. São Paulo: Boitempo, 2018.

FOUCAULT, Michel. Vigiar e Punir. Rio de Janeiro: Vozes, 1979. FOUCAULT, Michel. Microfísica do Poder. Rio de Janeiro: Graal, 1984. 
FOUCAULT, Michel. História da sexualidade: A vontade de saber. Trad. 7a. Edição. Rio de Janeiro: Graal, 1985.

FOUCAULT, Michel. Em defesa da sociedade. São Paulo: Martins Fontes, 1999.

GRAHAM, Stephen. Cidades sitiadas. O novo urbanismo militar. São Paulo: Boitempo, 2016.

GUSI, João Antônio Ferreira. O estado de exceção de Giorgio Agamben: a força da norma. 2015. 112 f. Dissertação (Mestrado em Filosofia) - Pontifícia Universidade Católica do Paraná, Paraná, 2015.

GUSSO, Luana de Carvalho S.; SOUZA, Luís Antonio F. de; SERRA, Carlos Henrique A. Cidades ocupadas: Securitização, biopolítica e controle social no contexto da cidade globalizada na sociedade brasileira. Revista Crítica Penal y Poder, Barcelona, n. 20, 2020.

JAKOBS, Günther. Direito Penal do Cidadão e Direito Penal do Inimigo. In: JAKOBS, Günther; CANCIO MELIÁ, Manuel. Direito Penal do Inimigo. Noções e críticas. Porto Alegre: Livraria do Advogado, 2010.

LATOUR, Bruno. Jamais fomos modernos. Rio de Janeiro: Editora 34, 1994.

LEMKE, Thomas. A Zone of Indistinction - A Critique of GiorgioAgamben's Concept of Biopolitics. In: Bloßes Leben in der globalisierten Moderne. Eine Debatte zu Giorgio Agamben's Homo Sacer. Hannover: University of Hannover, 2003.

LEUTÉRIO, Alex Pereira. Estado de exceção na obra de Giorgio Abamben. Da politização da vida à comunidade que vem. 2014. 146 f. Dissertação (Mestrado em Direito) - Pontifícia Universidade Católica de São Paulo, São Paulo, 2014.

MACHADO DA SILVA, Luiz Antônio. Cidades controladas. O controle do crime violento na cidade do Rio de Janeiro. Le Monde Diplomatique Brasil, n. 67, fevereiro de 2013. 
MARTINS, Cristiano Zanin; MARTINS, Valeska; e VALIM, Rafael. Lawfare: uma introdução. São Paulo: Editora Contracorrente, 2019.

MBEMBE, Achille. Política da inimizade. Lisboa: Antígona, 2017. MBEMBE, Achille. Necropolítica. Bipoder, soberania, estado de exceção, política da morte. São Paulo: n-1 Edições, 2018.

PAOLIELLO, Tomaz; MIKLOS, Manoela. Militarização da segurança pública no Rio e em todo o mundo. Open Democracy. 04 october 2017. https://www.opendemocracy.net/pt/democraciaabierta-pt/ militariza-o-da-seguran-p-blica-no-rio-e-em-todo-o-/ Acesso em 04/08/2020.

REVEL, Judith. Dicionário Foucault. Rio de Janeiro: Forense Universitária, 2011.

RODRIGUES, André e SIQUEIRA, Raiza. As Unidades de Polícia Pacificadora e a segurança pública no Rio de Janeiro. In:

Unidades de Polícia Pacificadora: debates e reflexões. Rio de Janeiro: Comunicações do ISER, número 67, ano 31, 2012.

SANTOS, Laymert Garcia dos. Brasil contemporâneo: estado de exceção? In: A era da indeterminação. Rio de Janeiro: Boitempo, 2007.

SERRA, Carlos Henrique Aguiar. Criminologia e Direito Penal em Roberto Lyra e Nélson Hungria: uma proposta indisciplinada. Rio de Janeiro: Lumen Juris, 2008.

SCHMITT, Carl. Teologia Política. Belo Horizonte. Ed. Del Rey. 2006.

SILVA, Vinicius Felix da. O Estado de Exceção Pacificador: modulações e paradigmas da exceção em Agamben e na política pública de pacificação do Rio de Janeiro. Dissertação de Mestrado. UFABC, 2018.

SPAGNUOLO, Sérgio et al. Tá tudo dominado. As milicias assumiram o controle do Rio de Janeiro. The Intercept Brasil. 5 de 
(Des)encontros entre Giorgio Agamben e Michel Foucault: o que resta do Estado de direito no Brasil Carlos Henrique Aguiar Serra • Luís Antônio Francisco de Souza • Raphael Guazzelli Valério

abril de 2018. https://theintercept.com/2018/04/05/milicia-controle-rio-de-janeiro/?fbclid=IwAR1Ae2eB-WcWMt5CSIbdnXNdOTEl5xUoth155SSvbDabflB8-JRVuTVOVwc Acesso em 04/08/2020.

VALERIO, Raphael Guazzelli. Teoria biopolítica da formação humana. Curitiba: Editora UFPR, 2019.

ZAFFARONI, Eugênio Raul. Em busca das penas perdidas. Rio de Janeiro: Revan, 1991.

\section{6}

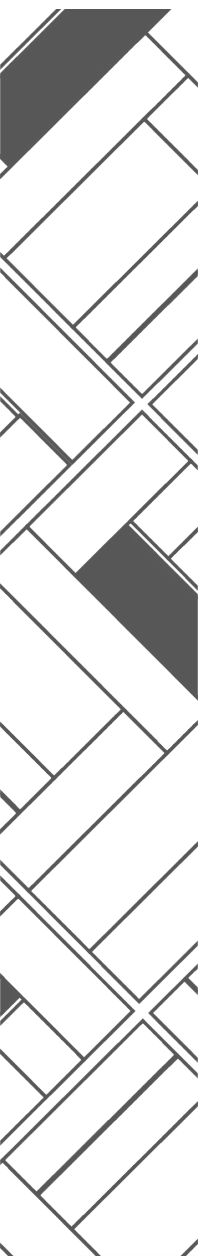

